\title{
Sociodemographic and lifestyle characteristics in relation to dietary patterns among young Brazilian adults
}

\author{
Maria Teresa A Olinto ${ }^{1, *}$, Walter C Willett ${ }^{2}$, Denise P Gigante ${ }^{3}$ and Cesar G Victora ${ }^{3}$ \\ 'Programa de Pós-Graduação em Saúde Coletiva, Universidade do Vale do Rio dos Sinos, Av. Unisinos 950, \\ 91.022-000, São Leopoldo, RS, Brazil: '²Department of Nutrition, Harvard School of Public Health, \\ Harvard University, Boston, MA, USA: ${ }^{3}$ Programa de Pós-Graduação em Epidemiologia, \\ Universidade Federal de Pelotas, Pelotas, RS, Brazil
}

Submitted 18 December 2008: Accepted 23 April 2010: First published online 25 June 2010

\begin{abstract}
Objective: To identify dietary patterns among young adults and the relationships with socio-economic, demographic and lifestyle characteristics.

Design: Population-based, cross-sectional analysis of a cohort study. Food intake was assessed by a frequency questionnaire, and dietary patterns were identified using principal components analysis.

Setting: Southern Brazil.

Subjects: A total of 4202 men and women aged 23 years, who participated in the 1982 Pelotas Birth Cohort Study.

Results: Five dietary patterns were identified: common Brazilian, processed food, vegetable/fruit, dairy/dessert and tubers/pasta. Subjects who had low own or maternal educational levels, low social position or who were always poor throughout life had high adherence to the common Brazilian dietary pattern. In contrast, the processed food pattern was more likely to be followed by those belonging to middle and high social position and who were never poor. Men and smokers showed high adherence to the processed food and common Brazilian dietary patterns. Vegetable/ fruit pattern was more likely to be followed by women and subjects engaged in physical activity. Women also showed high adherence to the dairy/dessert pattern. Conclusions: Our study among young Brazilian adults has identified distinct dietary patterns that are clearly influenced by socio-economic and lifestyle characteristics, which have important policy implications in a country with marked social and economic inequalities.
\end{abstract}

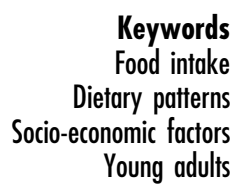

Keywords

Food intake

Young adults
Dietary pattern analysis has become common in nutritional epidemiology. Coherence among findings from studies of dietary patterns and from traditional approaches focusing on individual foods and nutrients has contributed to knowledge about the relation of nutrition and disease. Empirically derived dietary patterns are obtained from the transformation of a large set of correlated food variables into a new smaller set of uncorrelated variables, known as dimensions or patterns. A 2004 global literature review identified over ninety quantitative studies investigating population dietary patterns $^{(1)}$, mostly from developed countries.

During late adulthood, relatively consistent associations between diet and social, economic and lifestyle characteristics have been observed. With few exceptions ${ }^{(2)}$, diets thought to be healthier have been strongly associated with higher socio-economic status (SES) and negatively with lifestyle factors such as smoking and inactivity ${ }^{(3-11)}$. In addition, better diet quality has been associated with older age $e^{(4,7,9)}$. However, few studies have been conducted on the relationship between dietary patterns and SES and lifestyle factors among young adults. Moreover, in these studies the variables used to assess social and economic characteristics have differed substantially ${ }^{(12-15)}$. Taken together, it is not possible to discern consistent findings from available studies among young adults.

We identified the major dietary patterns in a cohort of young adults living in southern Brazil, born in 1982, and then examined the association between these dietary patterns and their socio-economic, demographic and lifestyle characteristics. This data set is one of the largest and longest-running birth cohorts from a developing country ${ }^{(16)}$, but dietary patterns have not previously been investigated in this cohort.

\section{Methods}

\section{Background}

In 1982, a population-based birth cohort study was initiated in Pelotas, a medium-sized city in the extreme south of Brazil, which included all 5914 live-born infants during 
that year. Since these baseline data were collected, this cohort was followed in 1984, 1986, 1997, 2001 and 20042005. Initially, the study centred on perinatal (baseline study), infant and early childhood morbidity and mortality, with a particular focus on breast-feeding patterns and nutritional status. When the cohort members became young adults, the emphasis shifted to risk factors for chronic disease, including diet and physical activity. During the eighth follow-up, from October 2004 to August 2005, 4297 cohort members were located and interviewed. In addition, the mortality monitoring system identified 282 cohort members who had died. The follow-up rate including those interviewed and those that were known to have died - was $77 \cdot 4 \%$. The highest follow-up rates were in the upper socio-economic level. The methodological details of the follow-up have been published elsewhere ${ }^{(17)}$.

\section{Study population}

We studied 4297 cohort members located in 2004-2005 (average age: 23 years). In the present analysis, we used information collected from the perinatal study in 2004-2005.

The study was approved by the ethics committee of the Medical Faculty of the Federal University of Pelotas. Written informed consent was obtained from all subjects before the interview.

\section{Explanatory variables}

Socio-economic and demographic characteristics, smoking and information on physical activity were obtained through standardized questionnaires. Information on sex, skin colour, mother's education and income was collected at baseline in 1982. Variables collected at follow-up in 2004-2005 included family income, family social position, education (cohort members' years of schooling), physical activity and smoking status. In addition, weight was measured using a portable digital electronic scale with a capacity of $150 \mathrm{~kg}$ and precision of $0 \cdot 1 \mathrm{~kg}$ (Uniscale; SECA, Copenhagen, Denmark) and height was measured using a locally developed portable aluminium height instrument with a precision of $1 \mathrm{~mm}$. For analysis, the socio-economic and demographic explanatory variables were categorized using conventional cut-off points and/ or based on the distribution of responses as follows: sex (men and women), skin colour (white and not white), mother's education $(0-4,5-8,9-11$ and $\geq 12$ years of schooling), cohort members' education (0-4, 5-8, 9-11 and $\geq 12$ years of schooling) and current family social position from low to high (based on domestic assets, presence of servants and level of education of the head of the household, according to the standard Brazilian Economic Classification of social classes A-E) ${ }^{(18)}$. Income information, collected in 1982 and in 2004-2005, was used to create a variable labelled 'income change'. This variable measures change in the family income throughout life. We used tertiles of family income obtained at the baseline interview and at follow-up in 2004-2005 and combined them into a variable with four categories: always poor (equivalent to the lowest tertile of family income in 1982 and 2004-2005), non-poor $\rightarrow$ poor (second or third tertile in 1982 and lowest tertile in 2005), poor $\rightarrow$ non-poor (lowest tertile in 1982 and second and third tertiles in 2004-2005) and never poor (second or third tertile in 1982 and 2004-2005). Leisure-time physical activity was categorized as none or in tertiles of min/week (10-110; 120-299 and $\geq 300 \mathrm{~min} /$ week). Smoking was categorized as current smoker and non-smoker. BMI $\left(\mathrm{kg} / \mathrm{m}^{2}\right)$ was calculated to describe the nutrition status of the cohort member, but it was not our aim to investigate its association with dietary patterns.

\section{Dietary assessment variables}

Information on diet was collected during interviews carried out in 2004-2005. Usual intake over the past year was assessed by a semi-quantitative, interviewer-administered FFQ. A list of eighty-two food items in the FFQ was used to collect information on the frequency of food intake. Food serving intake (standard portion size) was specified for each food with response options ranging from 0 to 10 times per day, per week, per month or per year. The FFQ was derived from the National Survey on Household Expenses, but was limited to regional eating habits.

We collapsed eighty-two food items into forty-seven groups, by combining foods that were similar in nutrient profile and represented particular dietary habits of the south Brazilian population. Foods that were reported by more than $80 \%$ of the subjects remained as separate items (e.g. orange, banana, lettuce, rice and black beans).

From the 4297 subjects, we excluded fifty-two subjects on the basis of FFQ responses that did not appear to be plausible. The majority of these cases were due to clearly over-reported food intake, e.g. eating all food items everyday. In addition, we excluded forty-three men and women reporting energy intake $+3 \mathrm{sD}$ over the mean. Because only $0.4 \%$ of subjects reported total energy intake $<4186 \mathrm{~kJ} / \mathrm{d}$, they were not excluded. Thus, our study included 4202 young adults (2041 women and 2161 men).

\section{Statistical analysis}

We conducted a principal components factor analysis (PCA) to derive major dietary patterns based on fortyseven food groups. The factors were rotated by an orthogonal (Varimax) transformation. The number of factors retained was based on the following criteria: components with an eigenvalue of $>1$, scree plot test and the interpretability of the factors. The eigenvalues signify the amount of variance explained by each of the factors. Food items were considered to load on a factor if they had an absolute correlation $\geq 0 \cdot 30$ with the factor and thus were retained in the calculations of the dietary pattern scores.

Before identifying the dietary patterns, the reliability of the factor analysis procedure was assessed via the 
Kaiser-Meyer-Olkin (KMO) statistics and the Bartlett test of sphericity. To verify the consistency among subgroups, we performed the PCA stratified by sex.

Each of the five dietary patterns was categorized into tertiles. The highest tertile represented the greatest adherence to the dietary pattern. Poisson regression with robust variance was used in bivariate and multivariate analyses to allow the estimation of the prevalence ratio (PR) and 95\% CI for the highest tertile of each pattern compared to the lowest tertile. Variables with a level of significance $<20 \%$ in the bivariate analysis were included in the multivariable model. The model of multivariate analysis was based on a conceptual framework ${ }^{(19)}$, determined a priori. Two levels were incorporated into the multivariable model: level I included all socio-economic and demographic variables, and level II included lifestyle (physical activity and smoking status) and BMI variables. First-level variables were adjusted for each other and potential confounders $(P<0 \cdot 20)$ were kept for the adjustment of the second level. BMI was included in the second level as a potential confounder due to the close relationship with eating habits. A level of significance $<5 \%$ was adopted (all tests were two-tailed). PCA was performed by the Statistical Package for Social Sciences statistical software package version 16.0 (SPSS Inc., Chicago, IL, USA) and Poisson regression by the STATA statistical software package version 9.0 (StataCorp., College Station, TX, USA).

\section{Results}

Basic characteristics based on sex of the 4202 subjects are presented in Table 1. Men and women had the same mean age (23 years) and distribution of skin colour ( $24 \%$ non-white). The variable assessing change in family income from 1982 to 2004 showed that nearly $52 \%$ of the

Table 1 Socio-economic, demographic, anthropometric and behavioural characteristics according to gender in the 1982 Pelotas Birth Cohort Study (follow-up 2004-2005; $n$ 4202)

\begin{tabular}{|c|c|c|c|c|c|c|}
\hline \multirow[b]{2}{*}{ Characteristic } & \multirow{2}{*}{\multicolumn{2}{|c|}{$\frac{\text { Male }(n 2161)}{\%}$}} & \multirow{2}{*}{\multicolumn{2}{|c|}{$\begin{array}{c}\text { Female }(n \text { 2041) } \\
\% \\
\end{array}$}} & \multicolumn{2}{|c|}{ Total } \\
\hline & & & & & $n$ & $\%$ \\
\hline \multicolumn{7}{|l|}{ Mother's education (years of schooling) ${ }^{\star * *}$} \\
\hline $0-4$ & \multicolumn{2}{|c|}{$33 \cdot 2$} & \multicolumn{2}{|r|}{$32 \cdot 1$} & 1960 & $33 \cdot 2$ \\
\hline $5-8$ & \multirow{2}{*}{\multicolumn{2}{|c|}{$\begin{array}{l}42.5 \\
10.9\end{array}$}} & \multirow{2}{*}{\multicolumn{2}{|c|}{$\begin{array}{l}40 \cdot 6 \\
11 \cdot 3\end{array}$}} & 2454 & $41 \cdot 6$ \\
\hline $9-11$ & & & & & 654 & $654 \cdot 0$ \\
\hline$\geq 12$ & \multicolumn{2}{|c|}{$13 \cdot 4$} & \multicolumn{2}{|r|}{$15 \cdot 0$} & 838 & $838 \cdot 0$ \\
\hline \multicolumn{7}{|l|}{ Skin colour } \\
\hline White & \multirow{2}{*}{\multicolumn{2}{|c|}{$\begin{array}{l}75 \cdot 5 \\
24 \cdot 5\end{array}$}} & \multicolumn{2}{|r|}{$76 \cdot 0$} & 3182 & $75 \cdot 7$ \\
\hline Black/mixed & & & & $24 \cdot 0$ & 1020 & $24 \cdot 3$ \\
\hline \multicolumn{7}{|l|}{ Social position } \\
\hline $\mathrm{D}+\mathrm{E}$ (poorer) & \multicolumn{2}{|c|}{$44 \cdot 9$} & \multicolumn{2}{|r|}{$46 \cdot 9$} & 1922 & $45 \cdot 9$ \\
\hline C & \multicolumn{2}{|c|}{$35 \cdot 4$} & \multicolumn{2}{|r|}{$36 \cdot 1$} & 1496 & $35 \cdot 7$ \\
\hline$A+B$ (richer) & \multicolumn{2}{|c|}{$19 \cdot 7$} & \multicolumn{2}{|r|}{$17 \cdot 1$} & 773 & $18 \cdot 4$ \\
\hline \multicolumn{7}{|l|}{ Education (years of schooling) ${ }^{\star * *}$} \\
\hline $0-4$ & \multicolumn{2}{|c|}{$9 \cdot 3$} & \multicolumn{2}{|r|}{$6 \cdot 9$} & 341 & $8 \cdot 1$ \\
\hline $5-8$ & \multirow{2}{*}{\multicolumn{2}{|c|}{$\begin{array}{l}31 \cdot 8 \\
46 \cdot 2\end{array}$}} & \multicolumn{2}{|r|}{$22 \cdot 8$} & 1154 & $27 \cdot 5$ \\
\hline $9-11$ & & & & $51 \cdot 2$ & 2043 & $48 \cdot 6$ \\
\hline$\geq 12$ & & & & $19 \cdot 1$ & 664 & $15 \cdot 8$ \\
\hline Income change (from birth to 2004-2005) & & & & & & \\
\hline Always poor & & & & $17 \cdot 7$ & 683 & $16 \cdot 3$ \\
\hline Non-poor $\rightarrow$ poor & & & & $18 \cdot 0$ & 698 & $16 \cdot 6$ \\
\hline Poor $\rightarrow$ non-poor & & & & $14 \cdot 5$ & 644 & $15 \cdot 4$ \\
\hline Never poor & & & & $49 \cdot 8$ & 2176 & $51 \cdot 8$ \\
\hline BMI $\left(\mathrm{kg} / \mathrm{m}^{2}\right)^{\star}$ & & & & & & \\
\hline$<18 \cdot 5$ & & & & $7 \cdot 1$ & 248 & $5 \cdot 9$ \\
\hline $18 \cdot 5-24 \cdot 9$ & & & & $65 \cdot 7$ & 2721 & $64 \cdot 9$ \\
\hline $25 \cdot 0-29 \cdot 9$ & & & & $18 \cdot 0$ & 872 & $20 \cdot 8$ \\
\hline$\geq 30 \cdot 0$ & & & & $9 \cdot 2$ & 353 & $8 \cdot 4$ \\
\hline Physical activity during leisure time $e^{\star \star *}$ & & & & & & \\
\hline None & & & & $64 \cdot 9$ & 1950 & $46 \cdot 4$ \\
\hline 10 to $110 \mathrm{~min} /$ week & & & & $13 \cdot 0$ & 675 & $16 \cdot 1$ \\
\hline 120 to $299 \mathrm{~min} /$ week & & & & $13 \cdot 1$ & 813 & $19 \cdot 3$ \\
\hline$\geq 300 \mathrm{~min} /$ week & & & & $9 \cdot 0$ & 764 & $18 \cdot 2$ \\
\hline Current smoking** & & & & & & \\
\hline No & & & & $76 \cdot 6$ & 3137 & $74 \cdot 5$ \\
\hline Yes & & & & $23 \cdot 4$ & 1065 & $25 \cdot 3$ \\
\hline & Mean & SD & Mean & SD & Mean & SD \\
\hline Age (years) & $22 \cdot 70$ & 0.37 & $22 \cdot 70$ & 0.37 & - & - \\
\hline Physical activity during leisure time (min/week)* & $216 \cdot 90$ & $301 \cdot 20$ & $79 \cdot 70$ & $185 \cdot 60$ & $150 \cdot 00$ & $260 \cdot 90$ \\
\hline
\end{tabular}

$P$ values based on comparison of cohort members' characteristics between sexes using $\chi^{2}$ tests (Pearson's or trend) for categorical variables and $t$ test for continuous variables: ${ }^{* *} P<0 \cdot 01,{ }^{* *} P<0 \cdot 001$. 
Table 2 Factor loading for the major factors (dietary patterns) in young adults in the 1982 Pelotas Birth Cohort Study (follow-up 2004-2005; $n$ 4202)

\begin{tabular}{|c|c|c|c|c|c|}
\hline \multirow[b]{2}{*}{ Food group } & \multicolumn{5}{|c|}{ Dietary pattern } \\
\hline & Common Brazilian & Processed food & Vegetable/fruit & Dairy/dessert & Tubers/pasta \\
\hline Sugar & 0.687 & & & & \\
\hline White bread & 0.629 & & & & \\
\hline Coffee & $0 \cdot 618$ & & & & \\
\hline Butter/margarine & $0 \cdot 612$ & & & & \\
\hline Rice & 0.599 & & & & \\
\hline Black beans & 0.593 & & & & \\
\hline Hot dog/hamburger/cheeseburger & & 0.563 & & & \\
\hline Beer & & 0.525 & & & \\
\hline Red meat (steak/ground meat/pork) & & 0.503 & & & \\
\hline Processed meat (sausage/salami/ham) & & 0.494 & & & \\
\hline Snacks (kibe/filled pastry/empanada) & & 0.443 & & & \\
\hline Soda & & $0 \cdot 440$ & & & \\
\hline Mayonnaise & & $0 \cdot 420$ & & & \\
\hline Pizza & & 0.403 & & & \\
\hline Barbecuet & & 0.383 & & & \\
\hline French fries & & 0.359 & & & \\
\hline Canned vegetables/pickles & & $0 \cdot 350$ & & & \\
\hline Liver and organ meat & & $0 \cdot 314$ & & & \\
\hline Other vegetables and legumes & & & 0.607 & & \\
\hline Yellow-dark vegetables & & & 0.603 & & \\
\hline Cruciferous vegetables & & & 0.593 & & \\
\hline Lettuce & & & 0.560 & & \\
\hline Other fruit (other than banana and orange) & & & 0.514 & & \\
\hline Tomato & & & 0.507 & & \\
\hline Onion/garlic & & & $0 \cdot 439$ & & \\
\hline Fruit juice/fruit pulp juice & & & 0.304 & & \\
\hline Milk & & & & 0.688 & \\
\hline Chocolate (powder/bar) & & & & 0.672 & \\
\hline Yoghurt & & & & $0 \cdot 439$ & \\
\hline Cheese & & & & 0.400 & \\
\hline Banana & & & & $0 \cdot 365$ & \\
\hline Cake/puddings/candies/sweet cookies & & & & $0 \cdot 355$ & \\
\hline Potato/other tubers & & & & & 0.644 \\
\hline Manioc flour & & & & & 0.599 \\
\hline Pasta/polenta & & & & & 0.389 \\
\hline Eggs & & & & & $0 \cdot 310$ \\
\hline Variance explained (\%)‡ & $8 \cdot 6$ & $7 \cdot 1$ & $4 \cdot 9$ & $3 \cdot 9$ & $3 \cdot 2$ \\
\hline
\end{tabular}

Food items with absolute loadings $\geq 0.3$ are shown.

†Traditional southern Brazilian habit.

$\ddagger$ The percentage of total variance accounted by all factors is $27 \cdot 6$.

subjects were never poor, in contrast to $16 \%$ who were poor throughout their lives. Even though the percentage of poor women at the 2004-2005 follow-up period was higher than for men $(35 \cdot 7 \% v .30 \cdot 2 \%)$, more women than men had higher education ( $>12$ years of schooling). Men reported higher levels of physical activity and current smoking status than women.

The factor analysis procedure indicated satisfactory reliability, i.e. $\mathrm{KMO}=0 \cdot 79$, and the Bartlett test of sphericity was statistically significant $(P<0 \cdot 001)$. We identified five major dietary patterns accounting for $27 \cdot 6 \%$ of total variance. Table 2 illustrates the correlations of the food items with each of the five dietary patterns (rank order of factor loadings $>0 \cdot 30$ ). The two dietary patterns with the largest eigenvalues were labelled as common Brazilian and as processed food dietary patterns. These explained $8 \cdot 6 \%$ and $7 \cdot 1 \%$ of the total variance, respectively. The high factor loadings for rice and black beans, one of the most popular meals across the whole country, led us to label this pattern as common Brazilian. The processed food dietary pattern presented moderately high factor loadings for processed food and red meat items in general. The other three dietary patterns were labelled vegetable/fruit, dairy/dessert and tubers/pasta, also according to the high factor loadings in food items.

The PCA was also performed separately for each sex. The dietary patterns identified in men and women showed high consistency with each other, and with those obtained using the entire data set (presented in Table 2). The only difference noticed was that among women, foods used in preparation, i.e. onion, garlic and bacon, were also correlated with the common Brazilian dietary pattern (data not shown in the tables).

Table 3 illustrates the mean intake frequencies of food servings of all food items retained in the dietary patterns, comparing the lowest and the highest tertiles of the five 
Table 3 Mean intake frequenciest of each food item comparing the lowest (T1) $v$. the highest (T3) tertiles across the dietary patterns

\begin{tabular}{|c|c|c|c|c|c|c|c|c|c|c|c|c|c|c|c|c|c|c|c|c|}
\hline \multirow[b]{3}{*}{ Dietary pattern/food item } & \multicolumn{4}{|c|}{ Common Brazilian } & \multicolumn{4}{|c|}{ Processed food } & \multicolumn{4}{|c|}{ Vegetables/fruit } & \multicolumn{4}{|c|}{ Dairy products } & \multicolumn{4}{|c|}{ Tubers/pasta } \\
\hline & \multicolumn{2}{|c|}{$\mathrm{T} 1$} & \multicolumn{2}{|c|}{ T3 } & \multicolumn{2}{|c|}{$\mathrm{T} 1$} & \multicolumn{2}{|c|}{ T3 } & \multicolumn{2}{|c|}{ T1 } & \multicolumn{2}{|c|}{ T3 } & \multicolumn{2}{|c|}{$\mathrm{T} 1$} & \multicolumn{2}{|c|}{ T3 } & \multicolumn{2}{|c|}{$\mathrm{T} 1$} & \multicolumn{2}{|c|}{ T3 } \\
\hline & Mean & SD & Mean & SD & Mean & SD & Mean & SD & Mean & SD & Mean & SD & Mean & SD & Mean & SD & Mean & SD & Mean & SD \\
\hline \multicolumn{21}{|l|}{ Common Brazilian } \\
\hline Sugar & $214^{\star \star *}$ & 202 & 756 & 442 & 469 & 393 & 447 & 376 & $493^{\star \star \star}$ & 420 & 435 & 385 & $445^{\star}$ & 345 & 474 & 422 & $439^{\star \star}$ & 390 & 481 & 388 \\
\hline White bread & $48^{\star \star \star}$ & 222 & 858 & 348 & 592 & 431 & 564 & 371 & $612^{\star \star \star}$ & 422 & 568 & 417 & $507^{\star \star \star}$ & 350 & 648 & 440 & $517^{\star \star \star}$ & 352 & 654 & 455 \\
\hline Coffee & $34^{\star \star \star}$ & 208 & 666 & 477 & $434^{*}$ & 365 & 370 & 393 & $390^{*}$ & 399 & 421 & 399 & $440^{\star \star *}$ & 375 & 343 & 406 & $381^{*}$ & 391 & 417 & 403 \\
\hline Butter/margarine & $207^{\star \star \star}$ & 156 & 584 & 332 & 378 & 284 & 366 & 286 & 370 & 298 & 388 & 293 & $336^{\star \star \star}$ & 256 & 413 & 305 & $396^{\star \star *}$ & 307 & 358 & 276 \\
\hline Rice & $365^{\star \star \star}$ & 157 & 689 & 261 & $546^{*}$ & 248 & 495 & 243 & 513 & 233 & 525 & 278 & $555^{\star \star \star}$ & 244 & 478 & 225 & $488^{\star \star *}$ & 223 & 561 & 286 \\
\hline Black beans & $210^{\star \star *}$ & 144 & 570 & 301 & $419^{*}$ & 273 & 346 & 260 & 366 & 271 & 384 & 282 & $438^{\star \star *}$ & 291 & 325 & 258 & $333^{\star \star \star}$ & 260 & 428 & 298 \\
\hline Processed food & & & & & & & & & & & & & & & & & & & & \\
\hline /hamburger & 84 & 89 & 47 & 65 & $34^{\star \star \star}$ & 38 & 152 & 143 & $99^{\star \star \star}$ & 128 & 75 & 85 & $84^{\star \star \star}$ & 103 & 89 & 95 & $76^{\star \star \star}$ & 92 & 101 & 129 \\
\hline Beer & $48^{\star \star \star}$ & 65 & 39 & 60 & $13^{\star \star \star}$ & 24 & 78 & 81 & 42 & 60 & 42 & 64 & $54^{\star \star \star}$ & 76 & 34 & 49 & $39^{\star \star}$ & 56 & 45 & \\
\hline Red meat & $179^{\star \star \star}$ & 145 & 147 & 146 & $92^{\star \star \star}$ & 89 & 243 & 177 & $150^{\star \star \star}$ & 137 & 178 & 156 & $149^{\star \star \star}$ & 155 & 180 & 149 & $140^{\star \star \star}$ & 123 & 193 & 166 \\
\hline d meat & $211^{\star \star \star}$ & 156 & 268 & 271 & $127^{\star \star \star}$ & 128 & 357 & 243 & $219^{\star \star \star}$ & 201 & 263 & 234 & $181^{\star \star \star}$ & 165 & 307 & 253 & $286^{\star \star *}$ & 249 & 219 & 182 \\
\hline Snacks & $69^{\star \star \star}$ & 95 & 55 & 91 & $25^{\star \star \star}$ & 43 & 111 & 126 & $68^{*}$ & 102 & 61 & 93 & $54^{\star \star \star}$ & 91 & 72 & 103 & $54^{\star \star \star}$ & 85 & 73 & 102 \\
\hline Soda & $211^{\star \star}$ & 227 & 246 & 345 & $111^{\star \star \star}$ & 130 & 371 & 426 & $289^{* * *}$ & 408 & 189 & 221 & $191^{* * *}$ & 245 & 275 & 370 & $255^{\star \star \star}$ & 343 & 212 & 23 \\
\hline Mayonnaise & 98 & 119 & 106 & 208 & $47^{\star \star \star}$ & 81 & 170 & 225 & $106^{\star \star \star}$ & 166 & 100 & 177 & $86^{\star \star \star}$ & 157 & 121 & 168 & $113^{\star}$ & 171 & 98 & 16 \\
\hline Pizza & $4^{\star \star \star}$ & 40 & 19 & 32 & $12^{\star \star \star}$ & 17 & 42 & 49 & 23 & 33 & 29 & 36 & $18^{\star \star \star}$ & 30 & 35 & 41 & $22^{\star \star \star}$ & 28 & 30 & \\
\hline Barb & $22^{\star \star \star}$ & 47 & 24 & 26 & $17^{\star \star \star}$ & 18 & 44 & 57 & $26^{\star \star \star}$ & 32 & 32 & 31 & $26^{\star \star \star}$ & 43 & 32 & 29 & $\left.27\right|^{\star *}$ & 29 & 32 & \\
\hline Fren & $54^{\star \star \star}$ & 66 & 75 & 94 & $37^{\star \star \star}$ & 46 & 95 & 101 & $69^{\star}$ & 88 & 62 & 79 & 66 & 87 & 63 & 77 & $42^{\star \star \star}$ & 50 & 92 & 103 \\
\hline getables/pickles & $52^{\star \star}$ & 71 & 44 & 76 & $24^{\star \star *}$ & 37 & 75 & 95 & $30^{\star \star \star}$ & 52 & 64 & 85 & $41^{\star \star \star}$ & 66 & 51 & 76 & 52 & 82 & 47 & \\
\hline Liver and organ meat & 36 & 41 & 26 & 65 & $11^{\star \star \star}$ & 24 & 39 & 73 & $13^{\star \star \star}$ & 31 & 34 & 66 & $31^{\star \star \star}$ & 66 & 19 & 41 & $15^{\star \star \star}$ & 32 & 36 & 7 \\
\hline Vegetables/fruit & & & & & & & & & & & & & & & & & & & & \\
\hline bles/legumes & $87^{\star \star \star}$ & 209 & 283 & 321 & 222 & 266 & 239 & 272 & $79^{\star \star \star}$ & 110 & & 327 & $266^{\star \star \star}$ & 298 & 208 & 254 & & 299 & 225 & 253 \\
\hline Yello & $185^{\star \star \star}$ & 200 & 144 & 171 & 156 & 189 & 161 & 177 & $64^{\star \star \star}$ & 77 & 277 & 234 & $141^{\star \star \star}$ & 179 & 176 & 198 & $126^{\star \star \star}$ & 154 & 198 & 207 \\
\hline Cruc & & 136 & 110 & 145 & 112 & 136 & 107 & 136 & $43^{\star \star \star}$ & 57 & 190 & 177 & 110 & 139 & 104 & 130 & $73^{\star \star \star}$ & 90 & 151 & 163 \\
\hline Lettl & $27^{\star *}$ & 138 & 111 & 162 & 112 & 150 & 121 & 147 & $46^{\star \star \star}$ & 63 & 205 & 191 & $98^{\star \star *}$ & 134 & 135 & 162 & 119 & 160 & 117 & 145 \\
\hline Othe & $344^{\star \star \star}$ & 395 & 244 & 294 & $267^{\star \star \star}$ & 359 & 321 & 367 & $142^{\star \star \star}$ & 162 & 467 & 462 & $187^{\star \star \star}$ & 243 & 392 & 435 & $248^{\star \star \star}$ & 327 & 351 & 394 \\
\hline & $20^{* \star \star}$ & 178 & 277 & 272 & $222^{\star \star \star}$ & 198 & 269 & 237 & $129^{\star \star \star}$ & 136 & 368 & 272 & $264^{*}$ & 256 & 244 & 217 & $287^{\star \star *}$ & & 234 & 219 \\
\hline Onio & $54^{\star \star *}$ & 272 & 272 & 509 & 495 & 390 & 50 & 410 & $300^{\star \star \star}$ & 294 & 700 & 452 & $584^{\star \star *}$ & 410 & 453 & 395 & $646^{\star \star *}$ & 462 & 402 & 33 \\
\hline Fruit juice & $159^{\star \star \star}$ & 189 & 193 & 313 & 183 & 329 & 176 & 236 & $104^{\star \star \star}$ & 177 & 254 & 347 & $126^{\star * *}$ & 214 & 225 & 321 & $134^{\star \star *}$ & 243 & 222 & 31 \\
\hline Dairy products & & & & & & & & & & & & & & & & & & & & \\
\hline Milk & & 236 & 224 & 301 & 232 & 298 & 225 & 236 & 229 & 281 & 241 & 264 & $68^{\star \star \star}$ & 105 & 428 & 327 & 242 & 290 & 225 & 25 \\
\hline Chocolate & $11^{* \star *}$ & 224 & 171 & 287 & $146^{\star \star \star}$ & 238 & 226 & 270 & $201^{\star \star}$ & 277 & 181 & 239 & $48^{\star \star \star}$ & 74 & 379 & 320 & $211^{\star \star \star}$ & 283 & 175 & 22 \\
\hline & $00^{\star \star *}$ & 136 & & 10 & $55^{\star \star \star}$ & 110 & 89 & 131 & $59^{* * *}$ & 110 & 94 & 13 & $24^{\star \star \star}$ & 48 & 13 & 165 & 77 & 134 & 75 & 11 \\
\hline Chees & $7^{\star \star \star}$ & 230 & 102 & 20 & $76^{\star \star \star}$ & 14 & 23 & 26 & $116^{\star \star \star}$ & 176 & 193 & 25 & $67^{\star \star \star}$ & 121 & 24 & 27 & $215^{\star \star \star}$ & 274 & 117 & 171 \\
\hline Banana & $119^{\star \star \star}$ & 141 & 181 & 281 & 156 & 226 & 150 & 211 & $107^{\star \star \star}$ & 157 & 214 & 280 & $82^{\star \star \star}$ & 103 & 233 & 297 & 151 & 232 & 164 & 211 \\
\hline Desserts/sweets & $285^{\star \star \star}$ & 250 & 367 & 449 & $238^{\star \star \star}$ & 271 & 409 & 404 & 327 & 367 & 340 & 370 & $205^{\star \star \star}$ & 209 & 459 & 457 & $268^{\star \star \star}$ & 284 & 403 & 42 \\
\hline Tubers/p & & & & & & & & & & & & & & & & & & & & \\
\hline d other tubers & $94^{\star \star \star}$ & 100 & 110 & 140 & 106 & 144 & 103 & 101 & $81^{* \star *}$ & 101 & 122 & 130 & $92^{*}$ & 114 & 103 & 117 & $52^{\star \star \star}$ & 50 & 168 & 157 \\
\hline Manic & $17^{\star \star \star}$ & 45 & 10 & 27 & 13 & 41 & 13 & 27 & $8^{* * *}$ & 31 & 19 & 42 & $10^{\star \star *}$ & 28 & 15 & 45 & $3^{\star \star \star}$ & 8 & 29 & \\
\hline Pasta/polenta & $116^{\star \star \star}$ & 94 & 131 & 137 & $102^{\star \star \star}$ & 95 & 141 & 126 & $116^{\star \star \star}$ & 112 & 130 & 111 & 124 & 127 & 122 & 100 & $84^{\star \star \star}$ & 56 & 174 & 153 \\
\hline Eggs & $91^{* * *}$ & 87 & 130 & 161 & $79^{\star \star *}$ & 89 & 153 & 157 & 118 & 131 & 112 & 126 & 113 & 139 & 117 & 120 & $77^{\star \star \star}$ & 76 & 158 & 170 \\
\hline
\end{tabular}

$P$ values based on comparison of food frequencies between the lowest and the highest tertiles of dietary patterns using $t$ test: ${ }^{\star} P<0.05,{ }^{* *} P<0 \cdot 01,{ }^{* \star \star} P<0.001$.

tNumber of food servings per year $(365 \mathrm{~d})$; shade represents the correspondent dietary pattern. 
dietary patterns per year. The high-frequency intake of common Brazilian food items can be clearly observed for both the lowest and highest tertiles of the five dietary patterns. However, the highest tertile of common Brazilian pattern shows the highest intake frequency of servings of sugar, white bread, coffee, rice and black beans. As expected, the largest differences between the extreme tertiles of all food intake frequency items were observed for the corresponding dietary pattern. It is noteworthy that the lowest $v$. highest tertile of vegetable/fruit dietary pattern showed a reduction in the mean of soda intake, respectively, $289 v$ v. 189 servings/year.

Associations of common Brazilian and processed food dietary patterns with sociodemographic and lifestyle variables are presented in Table 4. After adjustment in the multivariable analysis, the common Brazilian dietary pattern was more likely followed by subjects who had low own or maternal educational levels, with low social position or who were always poor. In contrast, the processed food pattern was more likely to be consumed by wealthier subjects; i.e. of middle and high social position, who were never poor, or who were poor at birth and became wealthier by 2004-2005. Both the main dietary patterns were more prevalent in men and current smokers.

Table 5 shows associations with the vegetable/fruit, dairy/ dessert and tubers/pasta dietary patterns. After controlling for potential confounders, subjects with high education $(\geq 12$ years of schooling), higher social position (A and B) and who were never poor had higher adherence to the dairy/ dessert dietary pattern (adjusted PR of 1.71 (95\% CI 1.31 , 2.23; $P<0.001), 1.37$ (95\% CI 1.22, 1.54; $P<0.001)$ and $1 \cdot 74$ (95\% CI $1 \cdot 43,2 \cdot 12 ; P<0 \cdot 001)$, respectively). The dairy/ dessert and vegetable/fruit dietary patterns were more likely to be followed by women and by non-smokers, in contrast to all other patterns. Vegetable/fruit was the only dietary pattern that did not show a significant association with socioeconomic variables after adjustment in the multivariable model. A higher adherence to the vegetable/fruit dietary pattern was found in subjects with high leisure-time physical activity (PR $=1 \cdot 44 ; 95 \% \mathrm{CI} 1 \cdot 31,1 \cdot 59)$. Similar to the common Brazilian pattern, the tuber/pasta dietary pattern was associated with lower levels of the socio-economic variables, but associated positively with physical activity.

\section{Discussion}

We identified five major dietary patterns among 4202 men and women aged 23 years, who participated in the Pelotas Birth Cohort Study in southern Brazil. The dietary patterns were labelled as common Brazilian, processed food, vegetable/fruit, dairy/dessert and tubers/pasta. All patterns were strongly associated with SES, except for vegetable/fruit. Dietary patterns show different adherence for men and women. Regarding lifestyle characteristics (smoking, physical activity and dietary patterns), we identified two behavioural trends: health-conscious and unhealthy, as described below.

The first pattern, the common Brazilian pattern, included sugar, white bread, coffee, butter/margarine, rice and black beans. A similar dietary pattern was identified in another study of adults in the north-east and south-east of Brazil ${ }^{(20)}$. The highest tertile (T3) of food items of the common Brazilian pattern presented higher means of food intake servings per year than any other food item in the whole table, except for onion/garlic. The second pattern, processed food, reflects a mix of foods contained in Western-type diets in studies carried out in different cultures $^{(9,21,22)}$. Red meat, processed meat, soda and mayonnaise show marked differences between the highest and lowest tertiles of this pattern. The third pattern, vegetable/ fruit, resembles a healthier dietary pattern commonly identified in other populations ${ }^{(7,9,23)}$, except that in our study this pattern lacked foods such as fish, olive oil or wine. The fourth pattern, the dairy/dessert pattern, was mainly composed of milk, cheese, yoghurt, chocolate and desserts/ sweets. The fifth dietary pattern, tubers/pasta, was also found in a previous study in southern Brazil, although that study also included beans in this pattern ${ }^{(4)}$.

Our findings showed notable socio-economic differences in young adults' dietary patterns. Adjusted analyses of the four socio-economic variables (mother's and own education, social position and income change) should be interpreted with some caution due to multi-collinearity between these variables. The common Brazilian pattern was popular among subjects who had low own or maternal education, low social position or who were always poor. Composed of low-priced foods - such as white bread, sugar, rice and black beans - this dietary pattern may express the lack of variability in the diets of the poor. On the other hand, wealthier subjects were more likely to follow the processed foods and dairy/dessert dietary patterns. The vegetable/fruit dietary pattern was associated with the subject's educational level in the crude analyses, but not after adjustment for other social covariates. Associations of socio-economic characteristics and dietary patterns have been observed in several earlier studies. In a multi-ethnic cohort study in Hawaii and Los Angeles ${ }^{(24)}$ of adults aged 45-75 years, higher level of education was positively associated with fruit and milk dietary pattern, and negatively with 'fat and meat' dietary pattern. Consumption of unhealthy diets was associated with low employment grade among middle-aged men in London ${ }^{(15)}$. In a study of women living in southern Brazil $^{(4)}$, dietary choices were strongly influenced by SES and were not dependent only on food prices.

Although the association of processed food and tubers/pasta dietary patterns with the subject's education disappeared in the adjusted analysis, the association with mother's education persisted. These findings suggest the existence of early life influences, with mother's education having a stronger role than the subject's own education. More studies should be conducted to investigate 
Table 4 Prevalence ratios (PR) and $95 \% \mathrm{Cl}$ comparing the highest $v$. the lowest tertiles of the main dietary patterns according to sociodemographic characteristics and lifestyle in 1982 Pelotas Birth Cohort Study (follow-up 2004-2005)

\begin{tabular}{|c|c|c|c|c|c|c|c|c|}
\hline \multirow[b]{2}{*}{ Level/variable } & \multicolumn{4}{|c|}{ Common Brazilian } & \multicolumn{4}{|c|}{ Processed food } \\
\hline & Unadjusted PR & $95 \% \mathrm{Cl}$ & Adjusted PR & $95 \% \mathrm{Cl}$ & Unadjusted PR & $95 \% \mathrm{Cl}$ & Adjusted PR & $95 \% \mathrm{Cl}$ \\
\hline \multicolumn{9}{|l|}{ Level It } \\
\hline Sex & 0.003 & & 0.016 & & $<0.001$ & & $<0.001$ & \\
\hline Men & Reference & - & Reference & - & Reference & - & Reference & - \\
\hline Women & 0.89 & $0.83,0.96$ & 0.92 & $0.86,0.98$ & 0.58 & $0.54,0.64$ & \multirow{2}{*}{\multicolumn{2}{|c|}{$P=0.077$}} \\
\hline Skin colour & \multicolumn{2}{|c|}{$P<0.001$} & \multicolumn{2}{|c|}{$P=0.052$} & \multicolumn{2}{|c|}{$P=0.06$} & & \\
\hline White & Reference & - & Reference & - & Reference & - & Reference & - \\
\hline Black/mixed & 1.51 & $1 \cdot 40,1 \cdot 62$ & 1.09 & $1 \cdot 02,1 \cdot 17$ & 0.91 & $0.83,1 \cdot 00$ & 1.09 & $0.99,1.20$ \\
\hline Mother's education (years of schooling) & \multicolumn{2}{|c|}{$P<0.001$} & \multicolumn{2}{|c|}{$P<0.001$} & \multicolumn{2}{|c|}{$P<0.001$} & \multicolumn{2}{|c|}{$P=0.003$} \\
\hline $0-4$ & Reference & - & Reference & - & Reference & - & Reference & - \\
\hline $5-8$ & 0.75 & $0 \cdot 70,0.80$ & 0.94 & $0 \cdot 88,1 \cdot 01$ & $1 \cdot 31$ & $1 \cdot 19,1 \cdot 45$ & $1 \cdot 14$ & $1 \cdot 03,1 \cdot 26$ \\
\hline $9-11$ & 0.44 & $0.37,0.52$ & $0 \cdot 76$ & $0.64,0.90$ & $1 \cdot 47$ & $1 \cdot 30,1 \cdot 67$ & $1 \cdot 17$ & $1 \cdot 02,1 \cdot 34$ \\
\hline$\geq 12$ & \multirow{2}{*}{\multicolumn{2}{|c|}{$\begin{array}{c}0.23 \\
P<0.001\end{array}$}} & 0.63 & $0.50,0.80$ & $1 \cdot 70$ & $1.53,1.90$ & $1 \cdot 22$ & $1 \cdot 07,1 \cdot 40$ \\
\hline Education (years of schooling) & & & \multicolumn{2}{|c|}{$P<0.001$} & \multicolumn{2}{|c|}{$P<0.001$} & \multicolumn{2}{|c|}{$P=0.381$} \\
\hline $0-4$ & Reference & - & Reference & - & Reference & - & Reference & - \\
\hline $5-8$ & $0 \cdot 81$ & $0 \cdot 76,0.87$ & 0.89 & $0.83,0.96$ & 1.53 & $1 \cdot 25,1 \cdot 88$ & $1 \cdot 29$ & $1.06,1.57$ \\
\hline $9-11$ & 0.54 & $0.50,0.58$ & $0 \cdot 74$ & $0.68,0.81$ & 1.64 & $1 \cdot 35,2 \cdot 00$ & $0 \cdot 21$ & $0.99,1.48$ \\
\hline$\geq 12$ & $0 \cdot 13$ & $0 \cdot 10,0 \cdot 17$ & 0.27 & $0.22,0.38$ & $2 \cdot 02$ & $1 \cdot 65,2 \cdot 48$ & $1 \cdot 25$ & $1 \cdot 01,1.56$ \\
\hline Social position $\ddagger$ & \multicolumn{2}{|c|}{$P<0.001$} & \multicolumn{2}{|c|}{$P<0.001$} & \multicolumn{2}{|c|}{$P<0.001$} & \multicolumn{2}{|c|}{$P<0.001$} \\
\hline$D+E$ (poorer) & Reference & - & Reference & - & Reference & - & Reference & - \\
\hline C & 0.59 & $0.54,0.64$ & 0.72 & $0.72,0.86$ & 1.44 & $1 \cdot 32,1 \cdot 57$ & $1 \cdot 23$ & $1 \cdot 11,1 \cdot 35$ \\
\hline$A+B$ (richer) & \multirow{2}{*}{\multicolumn{2}{|c|}{$0^{0.24} \quad P<0.001$}} & 0.56 & $0.46,0.69$ & \multirow{2}{*}{\multicolumn{2}{|c|}{$P<0.001$}} & \multirow{2}{*}{\multicolumn{2}{|c|}{$P<0.001 .31,1.64$}} \\
\hline Income change (from birth to 2004-2005) & & & \multicolumn{2}{|c|}{$P=0.027$} & & & & \\
\hline Always poor & Reference & - & Reference & - & Reference & - & Reference & - \\
\hline Non-poor $\rightarrow$ poor & 0.79 & $0.73,0.87$ & $1 \cdot 00$ & $0 \cdot 91,1 \cdot 10$ & $1 \cdot 37$ & $1 \cdot 14,1 \cdot 64$ & $1 \cdot 20$ & $0.99,1.44$ \\
\hline Poor $\rightarrow$ non-poor & $0 \cdot 86$ & $0.79,0.94$ & $1 \cdot 02$ & $0 \cdot 94,1 \cdot 12$ & $1 \cdot 78$ & $1 \cdot 51,2 \cdot 11$ & 1.54 & $1 \cdot 29,1 \cdot 81$ \\
\hline Never poor & $0 \cdot 43$ & $0.40,0.47$ & $0 \cdot 88$ & $0 \cdot 79,0.98$ & $2 \cdot 04$ & $1 \cdot 76,2 \cdot 36$ & $1 \cdot 43$ & $1 \cdot 21,1 \cdot 69$ \\
\hline \multicolumn{9}{|l|}{ Level II§ } \\
\hline Physical activity in leisure time & \multicolumn{2}{|c|}{$P<0.001$} & $P=C$ & & $P<0$ & & $P=$ & \\
\hline None & Reference & - & Reference & - & Reference & - & Reference & - \\
\hline $10-110 \mathrm{~min} /$ week & 0.91 & $0.81,1.07$ & 0.96 & $0.87,1.05$ & $1 \cdot 20$ & $1 \cdot 08,1 \cdot 35$ & 1.04 & $0 \cdot 94,1 \cdot 16$ \\
\hline $120-299 \mathrm{~min} /$ week & 0.83 & $0.74,0.92$ & 0.92 & $0.83,1.01$ & $1 \cdot 39$ & $1.26,1.53$ & $1 \cdot 09$ & $0.99,1.20$ \\
\hline$\geq 300 \mathrm{~min} /$ week & 0.79 & $0.71,0.88$ & 0.89 & $0.80,0.99$ & 1.50 & $1 \cdot 36,1 \cdot 64$ & $1 \cdot 14$ & $1 \cdot 03,1 \cdot 24$ \\
\hline Current smoking & $P<0$ & & $P<C$ & & $P<0$ & & $P<$ & 01 \\
\hline No & Reference & - & Reference & - & Reference & - & Reference & - \\
\hline Current & 1.50 & $1 \cdot 40,1 \cdot 61$ & $1 \cdot 15$ & $1 \cdot 08,1 \cdot 23$ & $1 \cdot 29$ & $1 \cdot 20,1 \cdot 39$ & $1 \cdot 40$ & $1 \cdot 31,1 \cdot 51$ \\
\hline
\end{tabular}


Table 5 Prevalence ratios (PR) and $95 \% \mathrm{Cl}$ comparing the highest $v$. the lowest tertiles of dietary patterns according to sociodemographic characteristics and lifestyle in 1982 Pelotas Birth Cohort Study (follow-up 2004-2005)

\begin{tabular}{|c|c|c|c|c|c|c|c|c|c|c|c|c|}
\hline \multirow[b]{2}{*}{ Level/variable } & \multicolumn{4}{|c|}{ Vegetable/fruit } & \multicolumn{4}{|c|}{ Dairy/dessert } & \multicolumn{4}{|c|}{ Tubers/pasta } \\
\hline & $\begin{array}{c}\text { Unadjusted } \\
\text { PR }\end{array}$ & $95 \% \mathrm{Cl}$ & $\begin{array}{l}\text { Adjusted } \\
\text { PR }\end{array}$ & $95 \% \mathrm{Cl}$ & $\begin{array}{c}\text { Unadjusted } \\
\text { PR }\end{array}$ & $95 \% \mathrm{Cl}$ & $\begin{array}{c}\text { Adjusted } \\
\text { PR }\end{array}$ & $95 \% \mathrm{Cl}$ & $\begin{array}{c}\text { Unadjusted } \\
\text { PR }\end{array}$ & $95 \% \mathrm{Cl}$ & $\begin{array}{c}\text { Adjusted } \\
\text { PR }\end{array}$ & $95 \% \mathrm{Cl}$ \\
\hline \multicolumn{13}{|l|}{ Level I† } \\
\hline Sex & \multicolumn{2}{|c|}{$P<0.001$} & \multicolumn{2}{|c|}{$P<0.001$} & \multicolumn{2}{|c|}{$P<0.001$} & \multicolumn{2}{|c|}{$P<0.001$} & \multicolumn{2}{|c|}{$P<0.001$} & \multicolumn{2}{|c|}{$P<0.001$} \\
\hline Men & Reference & - & Reference & - & Reference & - & Reference & - & Reference & - & Reference & - \\
\hline Women & $1 \cdot 77$ & $1 \cdot 64,192$ & $1 \cdot 78$ & $1 \cdot 64,1 \cdot 93$ & $1 \cdot 19$ & $1 \cdot 11,1 \cdot 30$ & $1 \cdot 17$ & $1 \cdot 09,1 \cdot 26$ & $0 \cdot 74$ & $0.68,0.79$ & 0.73 & $0.67,0.79$ \\
\hline Skin colour & \multicolumn{2}{|c|}{$P=0.191$} & \multicolumn{2}{|c|}{$P=0.045$} & \multicolumn{2}{|c|}{$P<0.001$} & \multicolumn{2}{|c|}{$P=0.061$} & \multicolumn{2}{|c|}{$P=0.268$} & & \\
\hline White & Reference & - & Reference & - & Reference & - & Reference & - & Reference & - & $\|$ & $\|$ \\
\hline Black/mixed & 1.06 & $0 \cdot 97,1 \cdot 15$ & 1.09 & $1 \cdot 00,1 \cdot 20$ & 0.66 & $0 \cdot 60,0 \cdot 74$ & 0.90 & $0.81,1 \cdot 00$ & $1 \cdot 05$ & $0.96,1 \cdot 14$ & - & - \\
\hline Mother's education (years of schooling) & \multicolumn{2}{|c|}{$P=0.746$} & & & \multicolumn{2}{|c|}{$P<0.001$} & \multicolumn{2}{|c|}{$P=0.008$} & \multicolumn{2}{|c|}{$P<0.001$} & \multicolumn{2}{|c|}{$P=0.001$} \\
\hline $0-4$ & Reference & - & \multirow{4}{*}{\multicolumn{2}{|c|}{$\|$}} & Reference & - & Reference & - & Reference & - & Reference & - \\
\hline $5-8$ & 0.99 & $0.91,1.08$ & & & $1 \cdot 40$ & $1 \cdot 17,1 \cdot 44$ & $1 \cdot 07$ & $0.95,1 \cdot 19$ & $0 \cdot 88$ & $0.81,0.96$ & 0.93 & $0 \cdot 86,1.02$ \\
\hline $9-11$ & 0.97 & $0.85,1 \cdot 06$ & & & $1 \cdot 84$ & $1 \cdot 48,1 \cdot 88$ & $1 \cdot 16$ & $1 \cdot 01,1 \cdot 32$ & $0 \cdot 74$ & $0.64,0.85$ & $0 \cdot 82$ & $0.71,0.96$ \\
\hline$\geq 12$ & 1.03 & $0.92,1 \cdot 16$ & & & $2 \cdot 18$ & $1 \cdot 18,2 \cdot 23$ & $1 \cdot 17$ & $1 \cdot 03,1 \cdot 33$ & 0.66 & $0.57,0.76$ & 0.76 & $0.65,0.91$ \\
\hline Education (years of schooling) & \multicolumn{2}{|c|}{$P<0.001$} & \multicolumn{2}{|c|}{$P=0.681$} & $P<0$ & .001 & $P<0$ & $0 \cdot 001$ & $P<0$ & .001 & $P=0$ & 0.929 \\
\hline $0-4$ & Reference & - & Reference & - & Reference & - & Reference & - & Reference & - & Reference & - \\
\hline $5-8$ & 0.99 & $0 \cdot 84,1 \cdot 16$ & 0.96 & $0 \cdot 82,1 \cdot 12$ & $1 \cdot 49$ & $1 \cdot 02,1 \cdot 65$ & $1 \cdot 19$ & $0.91,1.54$ & 0.85 & $0.75,0.95$ & 0.90 & $0 \cdot 80,1 \cdot 01$ \\
\hline $9-11$ & $1 \cdot 10$ & $0 \cdot 95,1 \cdot 28$ & 0.97 & $0 \cdot 84,1 \cdot 13$ & $2 \cdot 58$ & $1 \cdot 80,2 \cdot 81$ & $1 \cdot 59$ & $1 \cdot 23,2 \cdot 05$ & $0 \cdot 78$ & $0 \cdot 70,0$ & 0.95 & $0.84,1.07$ \\
\hline$\geq 12$ & $1 \cdot 23$ & $1 \cdot 04,1 \cdot 44$ & $1 \cdot 01$ & $0 \cdot 85,1 \cdot 22$ & 3.55 & $2 \cdot 42,3 \cdot 78$ & $1 \cdot 71$ & $1 \cdot 31,2 \cdot 23$ & 0.64 & $0.55,0.74$ & 0.94 & $0 \cdot 78,1 \cdot 13$ \\
\hline Social position & $P=0$ & 052 & $P=0$ & $0 \cdot 275$ & $P<0$ & .001 & $P<0$ & 0.001 & $P<0$ & .001 & $P=$ & 0.02 \\
\hline $\mathrm{D}+\mathrm{E}$ (poorer) & Reference & - & Reference & - & Reference & - & Reference & - & Reference & - & Reference & - \\
\hline C & $1 \cdot 10$ & $1 \cdot 01,1 \cdot 19$ & $1 \cdot 07$ & $0 \cdot 98,1 \cdot 17$ & $1 \cdot 71$ & $1 \cdot 56,1 \cdot 89$ & $1 \cdot 22$ & $1 \cdot 10,1 \cdot 35$ & $0 \cdot 84$ & $0.77,0.91$ & 0.90 & $0.82,0.99$ \\
\hline $\mathrm{A}+\mathrm{B}$ (richer) & 1.08 & $0.98,1.20$ & 1.06 & $0.93,1 \cdot 19$ & $2 \cdot 32$ & $2 \cdot 12,2 \cdot 53$ & $1 \cdot 37$ & $1 \cdot 22,1 \cdot 54$ & $0 \cdot 73$ & $0.65,0.82$ & 0.86 & $0.75,0.99$ \\
\hline Income change (from birth to & $P=0$ & 053 & $P=c$ & 0.06 & $P<0$ & .001 & $P<0$ & 0.001 & $P<0$ & .001 & $P=0$ & $0 \cdot 056$ \\
\hline Always poor & Reference & - & Reference & - & Reference & - & Reference & - & Reference & - & Reference & - \\
\hline oor $\rightarrow$ poor & 1.01 & $0 \cdot 88,1 \cdot 16$ & $1 \cdot 02$ & $0 \cdot 89,1 \cdot 18$ & $1 \cdot 60$ & $1 \cdot 30,1 \cdot 98$ & $1 \cdot 31$ & $1 \cdot 06,1 \cdot 62$ & $0 \cdot 86$ & $0.77,0.97$ & 0.94 & $0.84,1 \cdot 07$ \\
\hline Poor $\rightarrow$ non-poor & $1 \cdot 16$ & $1 \cdot 02,1 \cdot 33$ & $1 \cdot 19$ & $1 \cdot 04,1 \cdot 36$ & $2 \cdot 00$ & $1 \cdot 64,2 \cdot 45$ & $1 \cdot 66$ & $1 \cdot 35,2 \cdot 03$ & 0.92 & $0.82,1.03$ & 0.95 & $0.84,1.06$ \\
\hline Never poor & $1 \cdot 10$ & $0 \cdot 98,1 \cdot 23$ & $1 \cdot 11$ & $0 \cdot 97,1 \cdot 26$ & $2 \cdot 89$ & $2 \cdot 43,3 \cdot 45$ & $1 \cdot 74$ & $1 \cdot 43,2 \cdot 12$ & $0 \cdot 75$ & $0 \cdot 69,0.83$ & $0 \cdot 89$ & $0.79,1.00$ \\
\hline Level II§ & & & & & & & & & & & & \\
\hline Physical activity in leisure time & $P=0$ & 0132 & $P<0$ & $0 \cdot 001$ & $P<0$ & 001 & $P<0$ & $0 \cdot 001$ & $P<0$ & 001 & $P=0$ & 0.001 \\
\hline None & Reference & - & Reference & - & Reference & - & Reference & - & Reference & - & Reference & - \\
\hline $10-110 \mathrm{~min} /$ week & 0.90 & $0.81,1.02$ & 1.09 & $0 \cdot 98,1 \cdot 21$ & $1 \cdot 07$ & $0 \cdot 96,1 \cdot 21$ & $1 \cdot 08$ & $0 \cdot 91,1 \cdot 20$ & $1 \cdot 23$ & $1 \cdot 10,1 \cdot 36$ & $1 \cdot 15$ & $1 \cdot 03,1 \cdot 27$ \\
\hline 120-299 min/week & 0.97 & $0.88,1.08$ & $1 \cdot 18$ & $1 \cdot 07,1 \cdot 31$ & $1 \cdot 21$ & $1 \cdot 10,1 \cdot 34$ & $1 \cdot 14$ & $1 \cdot 05,1 \cdot 25$ & $1 \cdot 13$ & $1 \cdot 02,1 \cdot 25$ & $1 \cdot 08$ & $0.97,1.20$ \\
\hline$\geq 300 \mathrm{~min} /$ week & $1 \cdot 10$ & $1 \cdot 00,1 \cdot 21$ & $1 \cdot 44$ & $1 \cdot 31,1 \cdot 59$ & $1 \cdot 34$ & $1 \cdot 22,1 \cdot 47$ & $1 \cdot 26$ & $1 \cdot 15,1 \cdot 38$ & $1 \cdot 29$ & $1 \cdot 18,1 \cdot 42$ & $1 \cdot 22$ & $1 \cdot 10,1 \cdot 34$ \\
\hline Current smoking & $P=0$ & 053 & $P=C$ & 0.54 & $P<0$ & 001 & $P<0$ & 0.001 & $P=0$ & $\cdot 146$ & $P=0$ & $0 \cdot 421$ \\
\hline No & Reference & - & Reference & - & Reference & - & Reference & - & Reference & - & Reference & - \\
\hline Current & 0.91 & $0 \cdot 83,1 \cdot 00$ & 0.97 & $0 \cdot 89,1 \cdot 06$ & 0.6 & $0.54,0.67$ & 0.76 & $0 \cdot 68,0 \cdot 84$ & $1 \cdot 06$ & $0.98,1 \cdot 15$ & 0.96 & $0.89,1.05$ \\
\hline
\end{tabular}

tAdjusted for socio-economic and demographic (Level I) variables with $P$ value $<0 \cdot 20$ in the bivariable analysis.

fCurrent family social position.

of Level II (physical activity, smoking status and BMI) and potential socio-economic and demographic confounders from Level I ( $P$ value $<0 \cdot 20$ in the multivariable analysis).

\|Not included in multivariable analysis due to $P$ value $\geq 0.20$ in the bivariable analysis. 
the relationship between early life factors and dietary patterns.

We identified two main behavioural trends regarding lifestyle: health-conscious and unhealthy. The health-conscious behaviours were manifested in the strong and positive association of adherence to the vegetable/fruit dietary pattern and physical activity during leisure time. Similar findings were observed in a Greek study ${ }^{(25)}$. In addition, this finding is coherent with the reduction in soda intake for subjects with high adherence to the vegetable/fruit dietary pattern (Table 3 ). These results may be showing young adults making positive decisions with regard to their health, e.g. reducing intake of not healthy foods. In our study, non-smokers and physically active subjects showed high adherence to the dairy/dessert pattern. This 'conscious' behaviour could be based on guidelines promoting dairy diets as being healthy, although this beneficial effect has been recently called into question $^{(26,27)}$. On the other hand, physical activity was associated with the tubers/pasta dietary pattern, which might suggest a balance between energy expenditure and intake or even socio-economic residual confounding due to the relatively low cost of this pattern.

On the other hand, unhealthy behaviour trends were observed in subjects who smoked and reported high adherence to the processed food dietary pattern. Regarding the similarities of our processed food pattern with the Western-type diets, Sánchez-Villegas et al. ${ }^{(9)}$ pointed to the existence of dangerous behaviour clustering (smoking, sedentary lifestyle and unhealthy diets) in adults. Unhealthy lifestyle behaviour - including unhealthy eating habits, lower physical activity and smoking - has also been observed in studies of adolescents ${ }^{(25,28)}$.

We observed that women were more likely to follow the vegetable/fruit and dairy/dessert dietary patterns than men. Similar preferences for vegetables, fruit and dairy diets were found in other studies among women ${ }^{(24,29)}$. On the other hand, the common Brazilian, processed food and tuber/ pasta dietary patterns were more likely followed by men. Considering the types of foods included in those three dietary patterns, similar preferences were reported in men from another study ${ }^{(9,24)}$. Differences in diet quality between the sexes have been reported and diet quality reaches its lowest level for women in their mid-20s and for men in their mid-30s in developed countries ${ }^{(5)}$. This leads us to hypothesize that the differences in adherence according to sex in our findings will get stronger in mid-adulthood of our cohort. Another observation, perhaps related to gender roles, was that women were more likely than men to report foods such as onions, garlic and bacon that are used in preparation. Alternatively, this may indicate the existence of recall bias based on the different knowledge of men and women about food preparation details. After adjustment for covariates, the vegetable/fruit and the common Brazilian patterns presented borderline associations with skin colour. Black or mixed-colour subjects were 9\% more likely to follow both of these patterns. Regarding the common Brazilian pattern, this could reflect a cultural behaviour; i.e. black beans were originally a diet for slaves in Brazil's colonial period. In the north-east and south-east of Brazil, rice and beans showed higher intake among blacks ${ }^{(20)}$. Our findings on the vegetable/fruit pattern showed a consistent trend with a North American study showing that African Americans consumed more servings of fruit than European Americans ${ }^{(14)}$. In contrast, in another US study, African Americans showed lower diet quality compared with other racial groups ${ }^{(5)}$. We believe that conclusions regarding the relationship of race/ethnicity to diet types are not straightforward, especially for young adults among whom further studies are needed.

Finally, some methodological considerations should be addressed. This is a large-scale community-based birth cohort study, but it cannot be considered as representative of Brazil. In addition, there are inherent problems in dietary assessment, such as self-report bias, and frequency of food servings, rather than amount in grams, was used in this analysis. Furthermore, the PCA method is considered an a posteriori approach, because eating patterns are derived through statistical modelling of an available empirical data set ${ }^{(30)}$. Several subjective decisions are made in this process of analyses, such as the FFQ items definition, collapsing foods, defining the factor loading cut-off and number of factors and the labelling of the identified dietary patterns ${ }^{(1,31)}$. Those subjective decisions, however, are based on previous scientific knowledge and on our experience in nutritional epidemiological research.

In summary, our study among young Brazilian adults has identified distinct dietary patterns that are clearly influenced by socio-economic and lifestyle characteristics. Our investigation provided the opportunity to understand how cohort member characteristics might influence dietary patterns in early adulthood, which has important policy implications in a country with marked social and economic inequalities.

\section{Acknowledgements}

The 1982 birth cohort study is currently supported by the Wellcome Trust Initiative entitled 'Major Awards for Latin America on Health Consequences of Population Change'. Previous phases of the study were supported by the International Development Research Center, WHO, Overseas Development Administration, European Union, National Support Program for Centers of Excellence (PRONEX), the Brazilian National Research Council (CNPq) and Brazilian Ministry of Health. M.T.O. was supported by CAPES - Brazilian Government (process no. 434307-7). There are no conflicts of interest. All authors were involved in analysing the data, reviewing and interpreting the results and writing the manuscript. 


\section{References}

1. Newby PK \& Tucker KL (2004) Empirically derived eating patterns using factor or cluster analysis: a review. Nutr Rev 62, 177-203.

2. Rodrigues S, Caraher M, Trichopoulou A et al. (2008) Portuguese households' diet quality (adherence to Mediterranean food patterns and compliance with WHO population dietary goals): trends, regional disparities and socioeconomic determinants. Eur J Clin Nutr 62, 1263-1272.

3. Pryer JA, Cook A \& Shetty P (2001) Identification of groups who report similar patterns of diet among a representative national sample of British aged 65 years of age or more. Public Health Nutr $\mathbf{4}, 787-795$.

4. Lenz A, Olinto MT, Dias-da-Costa JS et al. (2009) Socioeconomic, demographic, and lifestyle factors associated with dietary patterns of women living in Southern Brazil. Cad Saude Publica 25, 1297-1306.

5. Forshee RA \& Storey ML (2006) Demographics, not beverage consumption, is associated with diet quality. Int J Food Sci Nutr 57, 494-511.

6. Sadakane A, Tsutsumi A, Gotoh T et al. (2008) Dietary patterns and levels of blood pressure and serum lipids in Japanese population. J Epidemiol 18, 58-67.

7. Costacou T, Bamia C, Ferrari P et al. (2003) Tracing the Mediterranean diet through principal components and cluster analyses in the Greek population. Eur J Clin Nutr 57, 1378-1385.

8. Schulze M, Hoffmann K, Kroke A et al. (2001) Dietary patterns and their association with food and nutrient intake in the European Prospective Investigation into Cancer and Nutrition (EPIC) - Postdam study. Br J Nutr 85, 363-373.

9. Sánchez-Villegas A, Delgado-Rodríguez M, Martínez-González MA et al. (2003) Gender, age, socio-economic and lifestyle factors associated with major dietary patterns in the Spanish Project SUN (Seguimiento Universidad de Navarra). Eur J Clin Nutr 57, 285-292.

10. Quatromoni PA, Copenhafer DL, Demissie S et al. (2002) The internal validity of a dietary patterns analysis. The Framingham Nutrition Studies. J Epidemiol Community Health 56, 381-388.

11. Brunner E, Mosdol A, Whitte DR et al. (2008) Dietary patterns and 15-y risks of major coronary events, diabetes, and mortality. Am J Clin Nutr 87, 1414-1421.

12. Nelson M, Gordon-Larsen P, North K et al. (2006) Body mass index gain, fast food, and physical activity: effects of shared environments over time. Obesity 14, 701-709.

13. Mikkilä V, Räsänen L, Raitakari O et al. (2007) Major dietary patterns and cardiovascular risk factors from childhood to adulthood. The Cardiovascular Risk in Young Finns Study. Br J Nutr 98, 218-225.

14. Deshmukh-Taskar P, Nicklas T, Yang S et al. (2007) Does food group consumption vary by differences in socioeconomic, demographic, and lifestyle factors in young adults? The Bogalusa Heart Study. J Am Diet Assoc 107, 223-234.

15. Martikainen P, Brunner E \& Marmot M (2003) Socioeconomic differences in dietary patterns among middleaged men and women. Soc Sci Med 56, 1397-1410.

16. Harpham T, Huttly SR, Wilson I et al. (2003) Linking public issues with private troubles: panel studies in developing countries. J Int Dev 15, 353-363.

17. Victora CG \& Barros AJ (2006) Cohort profile: The 1982 Pelotas (Brazil) Birth Cohort Study. Int J Epidemiol 35, 237-242.

18. ABEP (2003) Criterion of Brazilian Economic Classification. São Paulo: Brazilian Association of Research Institutes.

19. Victora CG, Huttly SR, Fuchs SC et al. (1997) The role of conceptual frameworks in epidemiological analysis: a hierarchical approach. Int J Epidemiol 26, 224-227.

20. Sichieri R, Castro JFG \& Moura AS (2003) Fatores associados ao padrão de consumo alimentar da população brasileira urbana. Cad Saude Publica 19, Suppl. 1, S47-S53.

21. van Dam RM, Rimm EB, Willett WC et al. (2002) Dietary patterns and risk for type 2 diabetes mellitus in US men. Ann Intern Med 136, 201-209.

22. Carrera PM, Gao X \& Tucker KL (2007) A study of dietary patterns in the Mexican-American population and their association with obesity. J Am Diet Assoc 107, 1735-1742.

23. Gao X, Chen H, Fung T et al. (2007) Prospective study of dietary pattern and risk of Parkinson disease. Am J Clin Nutr 86, 1486-1494.

24. Park S, Murphy S, Wilkens LR et al. (2005) Dietary patterns using the Food Guide Pyramid groups are associated with sociodemographic and lifestyle factors: the multiethnic cohort study. J Nutr 135, 843-849.

25. Kourlaba G, Panagiotakos D, Mihas K et al. (2009) Dietary patterns in relation to socio-economic and lifestyle characteristics among Greek adolescents: a multivariate analysis. Public Health Nutr 12, 1366-1372.

26. Chan JM, Wang F \& Holly EA (2007) Pancreatic cancer, animal protein and dietary fat in a population-based study, San Francisco Bay Area, California. Cancer Causes Control 18, 1153-1167.

27. Willett WC (2008) Overview and perspective in human nutrition. Asia Pac J Clin Nutr 17, Suppl. 1, 1-4.

28. Larson NI, Story M, Perry CL et al. (2007) Are diet and physical activity patterns related to cigarette smoking in adolescents? Findings from project EAT. Prev Chronic Dis 4, 1-12.

29. Milligan RA, Burke V, Bielin LJ et al. (1998) Influence of gender and socio-economic status on dietary patterns and nutrient intakes in 18-year-old Australians. Aust $N Z \mathrm{~J}$ Public Health 22, 485-493.

30. Hu FB (2002) Dietary pattern analysis: a new direction in nutritional epidemiology. Curr Opin Lipidol 13, 3-9.

31. Martinez ME, Marshall JR \& Sechrest L (1998) Invited Commentary: factor analysis and the search for objectivity. Am J Epidemiol 148, 17-19. 